\title{
Psychological and pedagogical support of the educational process of students with disabilities in the context of professional education
}

\author{
Anna Kabushko, ${ }^{1,}$, Olga Artemenko ${ }^{2}$, Maria Kirillova ${ }^{3}$, Eugenia Shipilova $^{4}$, Elena \\ Andreeva ${ }^{5}$ \\ ${ }^{1}$ Stavropol state pedagogical Institute, 417 «A», Lenin sg, 355000, Stavropol, Russia
}

\begin{abstract}
The article presents theoretical and empirical approaches to the study of the process of psychological and pedagogical support of the educational process of students with disabilities in the context of professional education. The article considers theoretical approaches to the definition of "psychological and pedagogical support", its content aspects, due to the specifics of the construction of the educational process with students with disabilities. It is shown that changes in the educational process of students with disabilities often relate not so much to technological and organizational and methodological aspects as social and psychological ones. A program for accompanying students with disabilities in the context of professional pedagogical education is presented on the example of the Stavropol State Pedagogical Institute.
\end{abstract}

\section{Introduction}

Today, one of the primary guidelines of the state is the task aimed not only at creating equal conditions for obtaining education, but also at ensuring equal opportunities for active and effective participation in the life of society for all its members. This position is a priority at both the federal and regional levels and is implemented at all levels of education, which defines it as the flagship of philosophy, theory and practice of modern education.

The organization of professional education is of fundamental importance, since it is this type of education that is characterized as the most important stage in the life of every person, when the mastery of high-quality professional competencies, demanded professional skills and abilities, allowing not only to take place in the profession, but also to ensure financially their livelihoods. This stage is especially important for students with disabilities, because the process of professional education in this category is the most specific both because of its limitations, and because of the student's belonging to a certain nosological group, and because of the severity and severity of the existing defect, as well as because of the requirements for the qualifications of a future specialist in a particular professional sphere (profession).

\footnotetext{
*Corresponding author: ann_k77@mail.ru
} 
Despite the fact that the educational process for students has clearly formed theoretical and methodological foundations and is considered from various spheres and directions, the aspect of psychological and pedagogical support of the educational process in the context of professional education for students with disabilities is relevant, because allows:

- not only more comfortably adapt and immerse students in the process of professional education, but also provides an opportunity for better management of this process in accordance with the needs and capabilities of the personality of students with disabilities;

- qualitatively form students with disabilities professional interests and competencies corresponding to their psychophysical and physiological characteristics;

- to provide a detailed psychological and pedagogical study of the personality of a student with disabilities, to assess the dynamics of the formation of his professionally significant properties and qualities.

In addition, the study and solution of the problem of professional education of students with disabilities is impossible without considering it in the context of an inclusive approach, where the support of the educational process is of particular relevance. This is due to the fact that students with disabilities and their special educational needs make new demands on the organization of their professional education. The changes relate to technological, organizational-methodological, moral-psychological and other parameters, which determined a number of problematic issues regarding the qualitative and quantitative characteristics of the educational process, sufficient and favorable for psychological and pedagogical support of students with disabilities in the context of professional education and their socialization.

\section{Purpose of the Present Study}

Studies of the designated problem area determine the urgent need to study this process in the educational segment of pedagogical professional education of students with disabilities for the effective implementation of psychological and pedagogical support of the educational process of students; substantiation and development of various methods, techniques and procedures for accompanying students with disabilities, as well as criteria for assessing the results of their vocational training for a competitive and successful professional future. In this study, we not only studied the features and experience of psychological and pedagogical support of the educational process of students with disabilities in the context of professional education, but also identified a program for accompanying students in a professional pedagogical education on the example of Stavropol State Pedagogical Institute.

\section{Theoretical and methodological approaches to the organization of psychological and pedagogical support}

Psychological and pedagogical support is an indivisible system in the process of activity, with the help of which such socio-psychological and pedagogical conditions are created, aimed at the successful development and training of an individual subject of the educational process [7].

The concept of psychological support was formulated in 1993 by psychologists G. Bardier, I. Romazan, T. Cherednikova [1].

The analysis of special psychological and pedagogical literature allows us to conclude that the concept of "support" in the studies of various domestic scientists and specialists is considered from different points of view. 
The main content of psychological and pedagogical support meets the advanced ideas of foreign psychology, the main representatives of which are: A. Maslow, G. Allport, J. Mead, C. Rogers, M. Kuhn, I. Bloomer [18].

In turn, the ideas of psychological and pedagogical support are based on the provisions of both domestic psychology and domestic pedagogy, including the ideas of Ye.V. Bondarevskaya [2], I.A. Yakimanskaya [19], R.L. Krichevsky [9], who noted that "support" is a kind of system of professional activity that creates favorable conditions for the successful adaptation of a person to the conditions of his life.

To date, researchers have not come to a consensus regarding the definition and essence of escort. For example, N.S. Pryazhnikov [13] and S.N. Chistyakov [17] adhere to the point of view that "accompaniment" is a special form of teacher's activity, which is aimed at the interaction of providing assistance to the ward in the process of his personal growth, choice of methods of behavior and making basic decisions.

E.F. Zeer defined "support" as an indivisible process of studying, organizing, forming and correcting the professional growth of the teacher's personality [6].

N.L. Konovalova established this concept as the interaction of an accompanying person and an accompanying person, which is aimed at solving the actual life problems of the person being accompanied [8].

As a systemic integrative "technology" of social and psychological assistance to an individual, the very concept of "support" is understood by N. Osukhova [12].

After analyzing the literature on this issue, we can conclude that psychological and pedagogical support can be understood in several aspects:

- in essence, as the very professional activity of a teacher who is ready to provide assistance and assistance in the individual educational route of the student;

- a process that encompasses the entire set of purposeful sequential regular pedagogical actions that help the student to make an independent choice when solving certain educational problems [10];

- the relationship of the accompanying and accompanied;

- pedagogical technologies, which include a cycle of mutually complementary stages in the activities of the teacher and other specialists in the implementation of educational achievements by students;

- a system that characterizes the correlation and mutual influence of elements: goal, content, process and result.

Psychological and pedagogical support is of particular importance in relation to persons with disabilities and is understood as complex psychological, pedagogical and social support, as well as assistance to students in solving basic problems related to development, education, upbringing, socialization by specialists of various profiles, acting in a unified manner. [8].

Modern domestic scientists' (Grishaeva S.A., Mitrofanova A. Ye. [3], Gurova E.V., Laas N.I., Pritolyuk A.V., Romanov I.A. [4], Denisova O.A., Lekhanova O.L. [5], Litvinenko I.L., Tukarev P.Yu. [11], Radionova N.F., Tryapitsyna A.P. [14], Fominykh E.S. [15], Furyaeva T.V. [16], Shein Yu.P., Sheina L.P. [18]) experience has been accumulated in organizing inclusive education, adapting persons with disabilities to inclusive education at a university, psychological and pedagogical support of students with disabilities and educational process in the context of their professional education; described various aspects of the features of professional diagnostics, employment of students with disabilities, the conditions for their successful functioning in the labor market and the influence of social partnership on increasing the competitiveness of university graduates with disabilities, etc.

Research by scientists has confirmed that psychological and pedagogical support of persons with disabilities is focused on providing two interdependent processes: 
- accompaniment of the development of the student himself and support of the process of his teaching, upbringing and correction of existing deviations;

- an integrated technology, a special way of supporting the student's personality, helping him in solving the problems of development, training, education, correction and socialization.

The process of psychological and pedagogical support of the educational process of students with disabilities at Stavropol State Pedagogical Institute is based on the experience of foreign and domestic teachers and psychologists who studied this issue in different time periods of the past and present centuries and is based on the creation of comprehensive assistance to students with disabilities in mastering educational program of higher education, as well as correction of deficiencies in their physical and (or) mental development and socialization.

\section{Organizational aspects of the implementation of the program of psychological and pedagogical support of the educational process of students with disabilities in the conditions of Stavropol State Pedagogical Institute}

The creation of conditions for students with disabilities is one of the priority tasks of the development of the university as a scientific and educational center, transmitting the ideas of inclusive education and creating technologies for implementing this approach [16].

When implementing the program for accompanying students, one of the main areas of work is the psychological and pedagogical support of students with disabilities, ensuring their optimal development and successful integration into society.

The goal of psychological and pedagogical support for students with disabilities is to teach them to be independent in solving their own problems and difficulties, which involves knowing oneself, one's own resources and an adequate perception of the surrounding reality.

The priority tasks of the program of psychological and pedagogical support for students with disabilities studying at Stavropol State Pedagogical Institute are:

- $\quad$ assistance in solving urgent problems of learning and socialization, problems of relationships with classmates and teachers;

- development of an inclusive culture among both students and teachers and university staff.

Currently, the institute is implementing the following areas of psychological and pedagogical support for students with disabilities:

- $\quad$ carrying out diagnostic, psycho-corrective, rehabilitation work with students with disabilities;

- provision of advisory assistance to students, their parents, scientific and pedagogical staff of the institute in solving problems related to the organization of the educational process and the creation of special conditions for teaching people with disabilities;

- implementation of preventive measures to prevent the emergence of social maladjustment among students with disabilities;

- $\quad$ carrying out activities aimed at the formation of an inclusive culture;

- $\quad$ providing psychological support to all students, promoting their development and organizing a developing environment.

During the implementation of the program of psychological and pedagogical support in order to organize control over the progress of students with disabilities, timely identify and solve their problems in the learning process, SSPI conducts a series of monitoring: 
"Monitoring the attendance and progress of students", "Monitoring of satisfaction with the educational process of students", " Monitoring the employment of graduate students ", etc.

Such diagnostics makes it possible to identify problems in learning, attendance, in the degree of student satisfaction with the organization of the educational process, as well as preferences in subsequent employment and problems associated with adaptation in an academic group, etc.

In the process of diagnostics, it was revealed that, as a rule, difficulties in the learning process among students arise as a result of their chronic diseases, routine examinations and treatment, which entails problems in attendance at classes. In such cases, individual work with a specific student is organized. Each teacher in a distance format provides the student with lecture materials and assignments for self-study, if necessary, conducts online consultations, this work is accompanied by the curator of the academic group.

Based on the recommendations of the individual rehabilitation and habilitation program (IRHP), the student has the opportunity to switch to training using electronic and distance educational technologies. In addition, students with disabilities are given the right to choose, taking into account individual psychophysical characteristics, the form of the current and final certification (orally, in writing, using technical means, in the form of testing, etc.). Depending on the nosology, students are provided with educational and other information (lecture notes and practical training materials as handouts, adapted textbooks, visual teaching aids, layouts, models, curricula, guidelines for students and other educational and methodological materials, electronic educational methodological complexes for distance learning, etc.), in a format convenient for them.

If necessary, an adapted educational program (AEP HE) is developed for the student. An adapted educational program contains adaptive disciplines (modules) in the variable part (elective disciplines), special conditions for studying curriculum disciplines, including "Physical training", practical training and passing the state final certification.

In cases where problems associated with adaptation in the academic group are identified, psychologists and curators organize work aimed at rallying the academic group and adapting students with disabilities in it.

In accordance with the preferences in future employment, meetings with employers, field meetings in educational institutions, "Job Fairs", etc. are organized for students.

\section{Analysis of the results of the implementation of the program of psychological and pedagogical support of the educational process of students with disabilities in the conditions of Stavropol State Pedagogical Institute}

Having sufficient experience of working with students with disabilities, we can note that $30 \%$ of students have no interest in social and cultural life. Many of the students during the school period were homeschooled, and therefore their communication skills remained insufficiently formed, and sometimes even the lack of a need for communication with peers. As a rule, these students master the educational program sufficiently, but when asked about their leisure time, they answer that they do not attend extracurricular activities and do not want to, justifying this answer by the lack of time and academic workload.

In addition, some students $(20 \%)$ have low motivation to find a job; many students prefer to continue their studies at all levels of education or to live on welfare without engaging in work. This problem is relevant. It is important to reorient the student in time from a passive life position to an active (including labor) position, from "beneficiaries" to "benefactors". 
Low motivation for learning is another problem that we face in the process of implementing a program of psychological and pedagogical support for students with disabilities. As studies show, at the stage of career guidance and choice of profession, the plans of applicants are quite ambitious, and having entered the direction they have chosen, students quickly encounter difficulties in mastering their future profession. Or, on the contrary, they enter a field of study that is not interesting to them, but was chosen by their parents (or recommended) due to health limitations, and, as a result, we note a lack of interest in learning. In this regard, it becomes necessary to provide individualized advice to applicants with disabilities at the stage of choosing a future profession.

The process of implementing the program of psychological and pedagogical support for students with disabilities allowed us to identify a number of problems that students face in the learning process. These problems are diverse in nature, from academic to social issues. In the future, we plan to solve the above-described number of problems, such as involving students in the cultural and leisure life of the institute, motivating students to find employment and individualizing vocational guidance for applicants with disabilities.

\section{Conclusion and recommendation}

Psychological and pedagogical support of the educational process of students with disabilities is a complex technology for solving the problems of their education and socialization.

The process of psychological and pedagogical support of students with disabilities in the context of professional pedagogical education is considered by us as:

- a specially organized system and conditions in which the professional development of the student's personality is carried out;

- a process that includes the formation of a positive attitude and readiness for future professional teaching activities;

- the formation and improvement of professional interests, skills and competencies, the study and assessment of the individual and professional qualities of the individual, the provision of practical assistance in mastering the profession.

The process of psychological and pedagogical support in an educational organization should be provided, first of all, by specialists with real experience in solving urgent personal problems of students with disabilities. It is very important from the very beginning to lay down the correct scientific criteria for assessing the effectiveness of psychological and pedagogical support. Such criteria may be the demand and recognition of the support system on the part of students with disabilities and their parents; overcoming (absence) of learning difficulties and increasing the number of positively resolved personality problems; satisfaction with the educational process and a high degree of motivation to master the chosen profession.

\section{References}

1. G. Bardier, I. Romazan, T. Cherednikova, I want! Psychological support of the natural development of young children (Publishing house Piter, SPb, 1996)

2. Ye.V. Bondarevskaya, Theory and practice of personality-oriented education (Publishing House Bulat, Rostov-on-Don, 2000)

3. S.A. Grishaeva, A.Ye. Mitrofanova, Bulletin of the University 12, 155-162 (2018) DOI: $10.26425 / 1816-4277-2018-12-155-162$.

4. E.V. Gurova, N.I. Laas et al., University Bulletin 2, 130-135 (2019) DOI: $10.26425 / 1816-4277-2019-2-130-136$ 
5. O.A. Denisova, O.L. Lekhanova, Bulletin of Cherepovets State University 6(87), 15669 (2018) DOI: 10.2859/1994-0637-20-18-6-87-17.

6. Zeer, E.F. Personal developmental education (Publishing House RGPPU, Yekaterinburg, 2006)

7. E.I. Kazakova, Theoretical foundations for the development of a general education school (system-orientational approach) Diss....Candidate of Pedagogical Sciences (SPb, 1995)

8. N.L. Konovalova, Prevention of disorders in personality development during psychological support of schoolchildren (Publishing house of St. Petersburg University, SPb., 2000)

9. R.L. Krichevsky, If you are a leader...: Elements of management psychology in everyday work (Publishing house Delo, M., 1998)

10. V.A. Kudryavtsev, S.N. Kashtanova, World of Science, Culture, Education 4(71), 6365 (2018)

11. I.L. Litvinenko, P.Yu. Tukarev, Bulletin of Volgograd State University. Series 3. Economics. Ecology 21(21), 75-82 (2019) DOI: https: //doi.Org/10.15688/jvolsu3.2019.1.7

12. N.G. Osukhova, Psychological support of personality in crisis situations: experience of empirical research: monograph (Publishing house Varson, M., 2008)

13. N.S. Pryazhnikov, Professional self-determination: theory and practice: textbook manual for stud. higher. study. institutions (Publishing Center "Academy", M., 2008)

14. N.F. Radionova, A.P. Tryapitsyna, Research of the problems of higher pedagogical education as a way to improve the multilevel training of a specialist in the field of education: Research activities in improving professional training: Collective monograph (Publishing house of RSPU im. A.I. Herzen, SPb, 1999)

15. E.S. Fominykh, Kazan Pedagogical Journal 2, 151-157 (2017)

16. T.V. Furyaeva, Inclusive approaches in education: textbook for secondary vocational education (Publishing House Yurayt, M., 2020)

17. S.N. Chistyakova, Pedagogical support of self-determination of schoolchildren: methodological manual (Publishing house Academy, M., 2005)

18. Yu.P. Shein, L.P. Sheina, Bulletin of USUES. Science, education, economics. Series of economics 3(13), 44-48 (2015)

19. I.S. Yakimanskaya, Basics of personality-oriented education (Publishing house BINOM, M., 2013) 